\title{
Comparative Neurotoxicity of Tubulin-Binding Drugs: Inhibition of Goldfish Optic Nerve Regeneration'
}

\author{
Roger E. Davis, Barbara E. Schlumpf, and Paui. D. Klingfr \\ University of Michigan, Mental Health Research Institute and Neuroscience Laboratory, \\ 1103 East Huron, Ann Arbor, Michigan 48109
}

Received January 8, 1985; accepted April 24, 1985

\begin{abstract}
Comparative Neurotoxicity of Tubulin-Binding Drugs: Inhibition of Goldfish Optic Nerve Regeneration. Davis, R. E., SCHLUMPF, B. E., AND KLINGER, P. D. (1985). Toxicol. Appl. Pharmacol. 80, 308-315. Intraperitoneal or intraocular (io) injection of tubulin-binding drugs in goldfish, Carassius auratus L., inhibited axonal regeneration or restoration of functional synapses in optic axons following optic nerve crush. One eye was used to detect effects on regeneration and the other was kept intact to detect effects on maintenance of established optic circuits. Regeneration was assessed by measuring the time to reappearance of a visually evoked branchial suppression response. Three drugs, vincristine, vinblastine, and podophyllotoxin, administered semiweekly by ip injection, each inhibited regeneration at doses that did not impair maintenance of response. Similar results were previously reported for ip colchicine. Vincristine was several times more potent than podophyllotoxin or colchicine and 25 times more potent than vinblastine. Picropodophyllotoxin, an isomer of podophyllotoxin which has low affinity for tubulin, did not inhibit regeneration. The io experiments showed that maintenance of vision was reversibly inhibited by a single injection of $0.05 \mu \mathrm{g} / \mathrm{g}$ of colchicine but unaffected by $0.01 \mu \mathrm{g} / \mathrm{g}$, and that administration of the lower dose immediately following optic nerve crush inhibited regeneration. Intraocular lumicolchicine, a colchicine photoisomer which has low affinity for tubulin, did not inhibit maintenance or regeneration. In contrast, an io dose of vincristine sufficient to inhibit visual recovery also blocked maintenance of vision. Thus regeneration and maintenance effects could not be dissociated for io vincristine suggesting its mechanism of action on retinal cells is different. A conditioning lesion was shown to decrease the time to reappearance of the visually evoked branchial response following optic nerve crush, which indicates that it is a sensitive index of the rate of axonal outgrowth to the optic tectum. 1985 Academic Press, Inc.
\end{abstract}

Our laboratory is investigating the relative sensitivity of regenerating goldfish optic nerve fibers to colchicine and other tubulin-binding drugs (Davis and Benloucif, 1981; Davis et al., 1984). Tubulin-binding drugs inhibit microtubules and axonal transport with a resultant accumulation near the nucleus of materials that are necessary for normal neuronal function, growth, and development (Paulson and McClure, 1975; Hanson and

\footnotetext{
${ }^{1}$ This work was supported by the U.S. Environmental Protection Agency, Grant R-808064-02.
}

Edström, 1978; Ochs, 1982). Colchicine, for example, inhibits fiber outgrowth in mammalian neurons in vitro (Daniels, 1972), regeneration of peripheral nerve fibers in birds (Mellick et al., 1974), and axonal transport and synaptic transmission in bird optic axons (Perisic and Cuenod, 1972). Tubulin-binding drugs are also reported to inhibit axonal transport in optic axons of mammals (Bunt and Lund, 1974) and fish (Schönhartung et al., 1977) but their relative potency in inhibiting vision is poorly understood. The mechanism of action of these neuroactive mole- 
cules varies (Paulson and McClure, 1975; Palanivelu and Ludena, 1982; Owellen et al., 1972) and there is no database on their comparative neurotoxicity.

Previous experiments with colchicine showed that the goldfish optic nerve may be a convenient and sensitive preparation for measuring the relative toxicity of tubulinbinding drugs (Davis et al., 1984). Regeneration was induced by crushing the optic nerve within the orbit (Attardi and Sperry, 1963). The rate of regeneration was assessed by measuring the time to reappearance of a visually evoked suppression of branchial (breathing) movements. The branchial suppression response (BSR) is obtained by classical conditioning of the visual stimulus (the CS) to an electrical shock (the US). One optic nerve was crushed and the other was kept intact to detect nonspecific drug effects on maintenance of the BSR. Colchicine administered semiweekly by ip injection inhibited regeneration of optic axons following oplic nerve crush at doses that did not block visual functions of an intact optic nerve.

This report presents results obtained for ip administration of three additional drugs, which differ in tubulin-binding properties, vincristine and vinblastine sulfate, and podophyllotoxin (Paulson and McClure, 1975; Hanson and Edström, 1978). Reports that the blood-brain barrier excludes most colchicine (Bennett et al., 1981; Tomiwa et al., 1983) and vincristine (Castle et al., 1976) and that crushing the goldfish optic nerve ruptures the barrier (Kiernan and Contestabile, 1980) suggested that drug uptake may be greater in the crushed than in the intact nerve. This possibility was tested in a second experiment which examined whether recovery is also more susceptible to inhibition when the drug is injected intraocular (io).

The final experiment deals with the relationship between visual recovery and axonal regeneration. Recent experiments by others suggest that the time to recovery of some types of visual responses is controlled by a recovery lag process (Edwards et al., 1981) and may be insensitive to experimental variables which inhibit the arrival of regenerating axons in brain visual centers. We examined whether administering a conditioning lesion (Edwards et al., 1981) to enhance axonal outgrowth results in decreased time to reappearance of the visually evoked BSR.

\section{METHODS}

Fish and CS-US conditioning. Goldfish (Carassius auratus, L.), 8 to $12 \mathrm{~g}$, obtaincd from Ozark Fisheries (Stoutland, Mo.), were kept in individual home tanks at $30^{\circ} \mathrm{C}$, the temperature being selected to obtain rapid regencration (Springer and Agranoff, 1977). Fish were conditioned in individual tanks, as previously described (Davis et al., 1984). The water was kept at $30^{\circ} \mathrm{C}$ and changed at the start of each session. Branchial ventilation movements were detected by the thermistor method (Davis, 1981). The CS consisted of the flickering movement of a spot of red light produced by alternately illuminating two light-emitting diodes that were centered one above the other $1 \mathrm{~cm}$ apart. Similar pairs of diodes were submerged in the water opposite each eye. The lower diode was kept lit during the intertrial interval. The duration of the CS interval in a trial was 2 or $5 \mathrm{sec}$ during which the upper and lower diodes were illuminated alternately every $250 \mathrm{msec}$. The US was a 0.5 -sec pulse from 7 to $8 \mathrm{~mA}$ (RMS) $60 \mathrm{~Hz}$ constant current that was passed between two steel electrodes on opposite sides of the fish holder instantaneously on the termination of the CS.

Fish screened for responding to the CS in right and left eye trials (Davis et al., 1984) subsequently received a preoperative test session consisting of several warm-up trials followed by eight, 5-sec test trials, four with the right (R) eye and four with the left (L) eye. A 5-sec blank trial was administered prior to each test trial. Fish that responded in each $R$ and $L$ eye test trial and showed no false positive responses in blank trials were accepted as subjects. This session was administered within several days prior to the day of surgery which is designated as experimental Day 0 .

Surgery. The optic nerve was crushed approximately $2 \mathrm{~mm}$ from the nerve head by pinching it with a forcep. During surgery the fish was anesthetized in $0.04 \%$ trimethanemethylsulfonate (Sigma) in tank water buffered to pH 6.5 to 7.5 with Tris Fish Buffer (Sigma) and held in a moist paper towel on the stage of a dissecting microscope. The anesthetized fish was returned to the homc tank to rccover.

Experimental drugs. Vincristine sulfate (Sigma Chemical Co.), vinblastine sulfate (Eli Lily), and colchicine (Sigma Chemical Co.) were delivered in $0.15 \mathrm{M} \mathrm{NaCl}$ and $\beta$-lumicolchicine (Sigma), podophyllotoxin (Sigma; $\mathrm{mp}=175^{\circ} \mathrm{C}$ ), and picropodophyllotoxin (Wilson and 
Freidkin, $1967 ; \mathrm{mp}=214^{\circ} \mathrm{C}$ ) in PET-80 which consisted of $3 \%$ ethanol, $0.3 \%$ Tween- 80 , and $10 \%$ propylene glycol in $0.15 \mathrm{M} \mathrm{NaCl}$. The volume of each injection was $1 \mu \mathrm{l} / \mathrm{g}$ of body weight on Day 0 .

Intraperitoneal assay protocol and data analysis. Fish received R-optic nerve crush on Day 0 and an ip administration of the drug the day before surgery and following each postaxotomy test session. The number of fish per group ranged from 5 to 10 , and the median was 9. The L-optic nerve was kept intact. The test sessions were given twice weekly beginning at 4 days postaxotomy (DPA). The procedure in each session was the same as in the preoperative test session.

The data for each session were reduced by computing the ratio of the average BSR (percentage suppression) in $\mathrm{R}$ trials and the average BSR in $\mathrm{L}$ trials for each fish. The ratio is denoted as the sightedness (S) score. In normal controls, the $\mathrm{S}$ score is not significantly different from unity. Prior to visual recovery in optic nerve crush fish that receive no drug, the $S$ score is not significantly different from zero. Individuals that stopped responding with the intact eye were eliminated from analysis of drug effects on visual recovery. This means that variations in the $\mathrm{S}$ score show effects on recovery and not maintenance of visual responding (Davis et al., 1984).

The effect of drug dose was evaluated by contrasting the mean $\mathrm{S}$ scores of the various groups in Day 21 in a $t$ test or a one-way ANOVA. Twenty-one days was taken as an approximation of the time following axotomy when the mean $\mathrm{S}$ score for control fish approached unity. Relative neurotoxicity was expressed as the $50 \%$ effective dose (ED50) which is the dose that is estimated to produce a mean $\mathrm{S}$ score of 0.5 on 21 DPA. The 21day ED50 and $95 \%$ confidence limits were derived from the regression of the mean $\mathrm{S}$ score against the log of the dose +1 (Davis et al., 1984).

Intraocular assay protocol. We first assessed the potency of io colchicine and vincristine in blocking maintenance of vision with the intact eye. To do this assessment, fish were anesthetized, administered a 10- $\mu$ l io injection of drug in the $\mathrm{R}$ eye on Day 0 and returned to the home tank to recover. Vision with the $\mathrm{R}$ and $\mathrm{L}$ eye was tested on Day $I$ and at varying intervals until Day 21. Subsequently, we investigated whether a dose that is ineffective or minimally effective in blocking maintenance inhibits recovery of vision. The drug was administered io immediately following optic nerve crush and the fish was returned to the home tank to recover.

Conditioning lesion procedure. Fish screened for responding to the $\mathrm{CS}$ as described above received a right optic nerve crush as a conditioning lesion 7 days $(N$ $=9), 14$ days $(N=9)$, or 42 days $(N=9)$ prior to another crush, at approximately the same location as a test lesion. Fish were kept at 25 or $30^{\circ} \mathrm{C}$. Semiweekly sessions of test trials were administered to obtain the mean period of days to $50 \%$ recovery of right-eye sightedness $(S=0.5)$ for each group.

\section{RESULTS}

Toxicity of ip tubulin-binding drugs. Vincristine inhibited recovery of $\mathrm{R}$-eye sightedness, and the effect increased with the dose in the range of 0.005 to $0.05 \mu \mathrm{g} / \mathrm{g}$ body weight (Fig. 1). The mean $\mathrm{S}$ score on Day 21 varied with the dose $[F(3,31)=12.15, p$ $<0.01]$ and the ED50 was $0.02(0.004$ to $0.034) \mu \mathrm{g} / \mathrm{g}$. High doses were lethal; two out of nine fish given $0.075 \mu \mathrm{g} / \mathrm{g}$ and six out of nine given $0.01 \mu \mathrm{g} / \mathrm{g}$ died between 14 and 25 days postaxotomy. The fish that died received a total of five to seven semiweekly injections; a few ceased responding with the intact $(\mathrm{L})$ eye in the session immediately prior to their demise. Otherwise, maintenance of visual responding appeared to be unaffected by vincristine.

Vinblastine inhibited visual recovery increasingly with the dose up to $1.25 \mu \mathrm{g} / \mathrm{g}$ body $w t$ (Fig. 2). The mean $\mathrm{S}$ score on Day 21 varied with the dose $[F(3,36)=4.32, p$ $<0.01]$ and the ED50 was $0.53(0.18$ to 1.0$)$ $\mu \mathrm{g} / \mathrm{g}$. Responding with the intact eye was maintained, and there was no dose-related mortality in fish receiving up to $3.0 \mu \mathrm{g} / \mathrm{g}$.

Podophyllotoxin inhibited visual recovery at doses between 0.01 and $0.25 \mu \mathrm{g} / \mathrm{g}$ (Fig. 3).

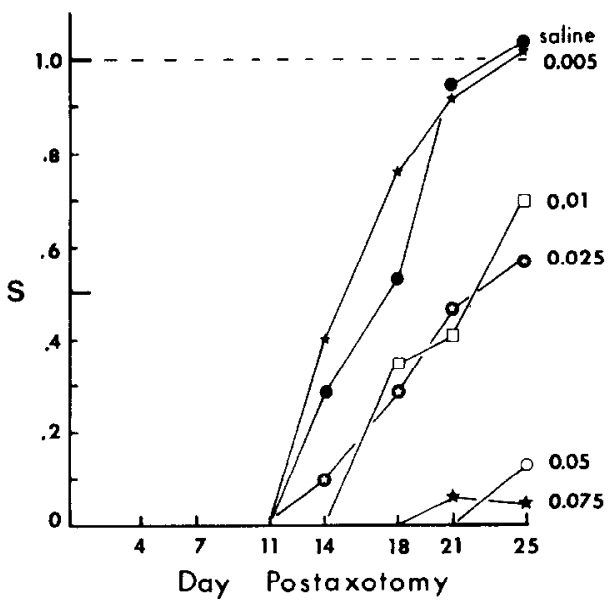

FIG. 1. Effects of ip administered vincristine on recovery of right (R)-eye sightedness following R-optic nerve crush. Mean S scores of less than 0.05 were not plotted. Dose units are $\mu \mathrm{g} / \mathrm{g}$ body wt. 


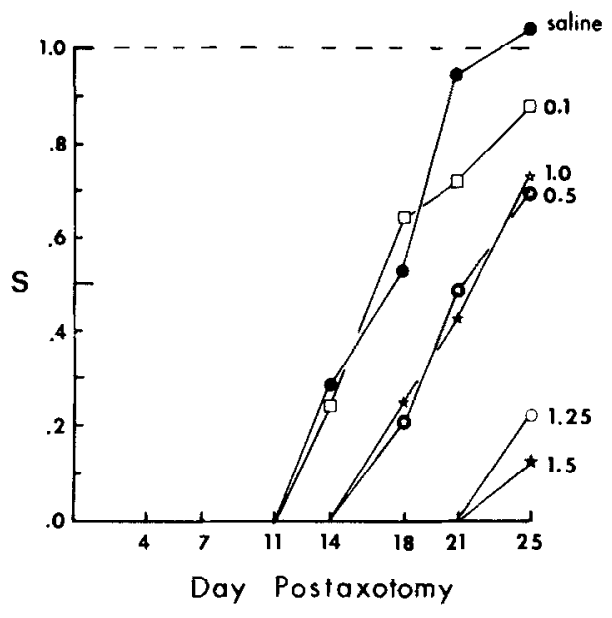

FIG. 2. Effects of ip administered vinblastine on recovery of right (R)-cyc sightedness following R-optic nerve crush. Mean $S$ scores of less than 0.05 were not plotted. Dose units are $\mu \mathrm{g} / \mathrm{g}$ body wt.

The mean S score on Day 21 varied with the dose $[F(3,31)=4.29, p<0.05]$ and the ED50 was 0.06 (0.03 to 0.17$)$. Responding with the intact eye was unaffected by doses up to 0.5 $\mu \mathrm{g} / \mathrm{g}$ which was the highest dose tested, and no fish died during the experiment. Picropodophyllotoxin, $0.5 \mu \mathrm{g} / \mathrm{g}$, or PET-80, $1 \mu \mathrm{l} /$ $\mathrm{g}$, did not inhibit visual recovery; as in the case of fish that received semiweekly ip ad-

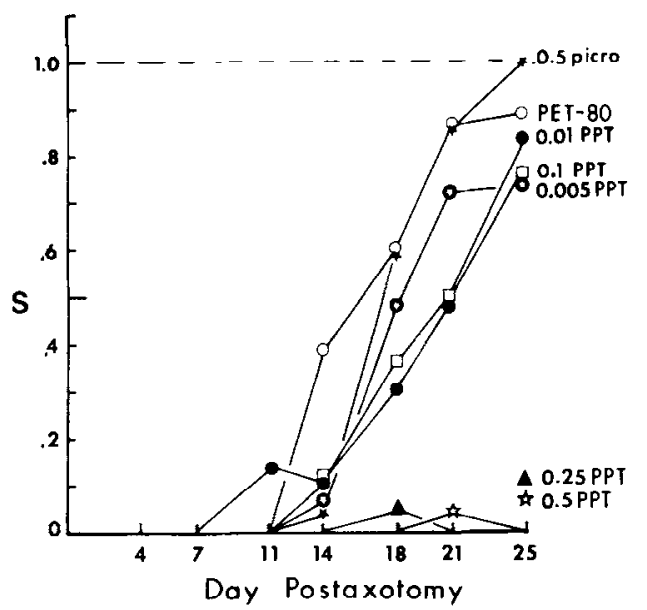

FIG. 3. Effects of ip administered podophyllotoxin (PPT), picropodophyllotoxin (Picro), or the vehicle (PET80 ) on recovery of right ( $R$ )-eye sightedness following $R$ optic nerve crush. Mean $S$ scores of less than 0.05 were not plotted. Dose units are $\mu \mathrm{g} / \mathrm{g}$ body wt. ministration of saline (Fig. 1), most showed recovery of $R$-eye sightedness between 11 and 21 DPA.

Toxicity of io tubulin-binding drugs. Maintenance of vision was inhibited by 0.05 but not $0.01 \mu \mathrm{g} / \mathrm{g}$ colchicine and $0.01,0.005$ but not $0.001 \mu \mathrm{g} / \mathrm{g}$ vincristine (Figs. 4 and 5). The ANOVA on the mean $\mathrm{S}$ score for the colchicine group was significant for dose $[F(1,15)=20.16, p<0.01]$, session $[F(6,90)$ $=7.02, p<0.01]$, and dose $\times$ session $[F(6,90)$ $=5.74, p<0.01]$. The ANOVA for vincristine groups also revealed significant dose $[F(2,24)=9.05, p<0.01]$, session $[F(4,96)$ $=21.09, p<0.01]$, and dose $\times$ session $[F$ $(8,96)=5.82, p<0.01]$ effects. The inhibitory effect of colchicine was reversed within 10 days. Behavioral testing several weeks following the experiment showed that the recovery was lasting. In contrast the blockade of vision by vincristine persisted. All but one fish administered the $0.005 \mu \mathrm{g} / \mathrm{g}$ dose showed impaired right-eye vision during the experiment (Fig. 4) and 3 weeks later their vision was still impaired. Responding in L-eye trials was normal throughout these experiments and revealed no effects of the colchicine or vincristine administrations in the $R$ eye.

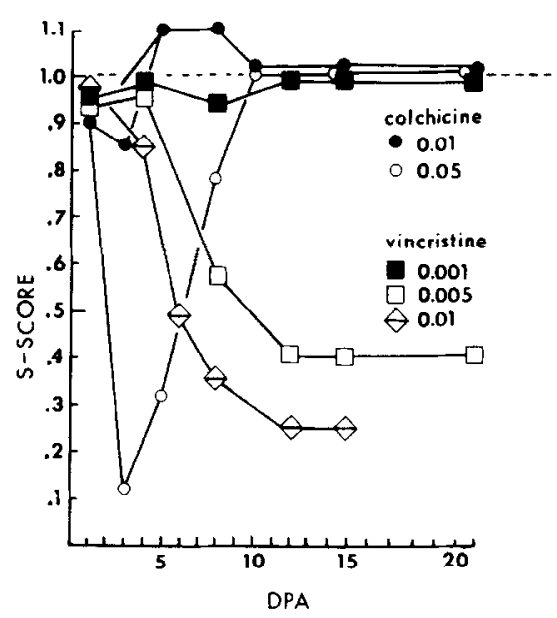

FIG. 4. Effect of an io injection of colchicine or vincristine on maintenance of vision. The drug was administered to the intact eye on Day 0 . An $\mathrm{S}$ score of 1.0 signifies normal vision. Dose units are $\mu \mathrm{g} / \mathrm{g}$ body wt. 


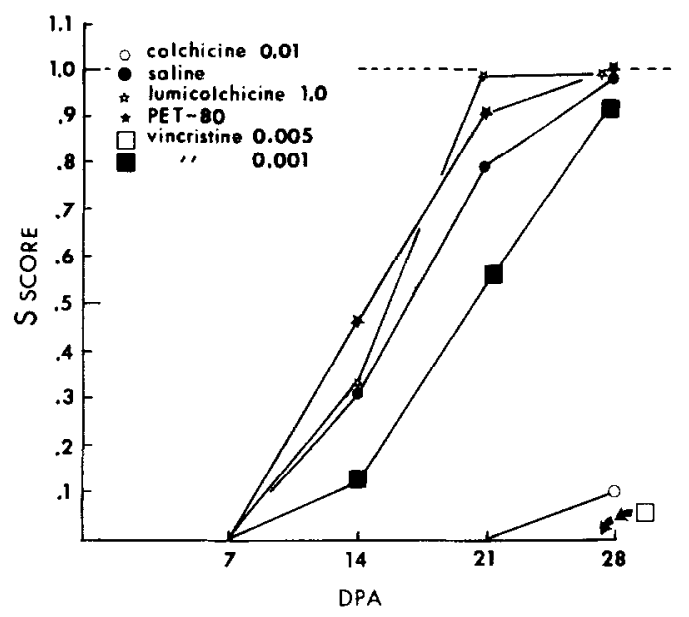

FIG. 5. Inhibition of the recovery of vision following optic nerve crush by io colchicine or vincristine. The drug was administered immediately following the nerve crush on Day 0 . Dose units are $\mu \mathrm{g} / \mathrm{g}$ body wt.

Visual recovery was inhibited by $0.01 \mu \mathrm{g} /$ $\mathrm{g}$ of colchicine which had no effect on maintenance of function (Figs. 4 and 5 ). The $\mathrm{S}$ scores of the saline and colchicine groups at 21 DPA were significantly different $(t$ $=8.30, p<0.01$ ). Fish administered $\beta$-lumicolchicine or PET-80 without a drug showed normal visual recovery. A one-way ANOVA on the mean $S$ score at 21 DPA revealed no significant difference between the lumicolchicine, PET-80, and saline groups $[F(3,26)$ $=1.63, p>0.05]$.

Vincristine inhibited visual recovery at 0.005 but not $0.001 \mu \mathrm{g} / \mathrm{g}$. An ANOVA on the mean $S$ scores for the vincristine- and the saline-treated fish showed a significant dose effect $[F(2,20)=28.24, p<0.01]$. The $21 \mathrm{DPA} S$ score of the $0.001 \mu \mathrm{g} / \mathrm{g}$ vincristine fish was different from that of the $0.005 \mu \mathrm{g} /$ $\mathrm{g}$ fish $[t=5.36, p<0.01]$ but not from that of the saline fish [ $t=1.96, p>0.05]$.

Conditioning lesion effect. The mean time to visual recovery following optic nerve crush was decreased by conditioning lesions in fish kept at $25^{\circ} \mathrm{C}$ but not at $30^{\circ} \mathrm{C}$ (Table 1). The recovery times for the three groups of $30^{\circ} \mathrm{C}$ fish were not significantly different $(p>0.05)$. The decreased recovery time obtained in $25^{\circ} \mathrm{C}$ fish did not vary significantly with the conditioning lesion interval.

\section{DISCUSSION}

Comparative toxicity of tubulin-binding drugs. Applications of tubulin-binding drugs that inhibit visual recovery after optic nerve crush but do not inhibit maintenance of response with the intact eye can be inferred to inhibit optic axon regeneration. These drugs are potent inhibitors of microtubules and axonal transport (Hanson and Edström, 1978; Ochs, 1982) which play essential roles in maintenance of normal neuronal functions, such as synaptic transmission (Perisic and Cuenod, 1972) as well as in nerve fiber growth, development, and regeneration (review: Grafstein and Foreman, 1980). The four tubulin-binding drugs so far examined each could be demonstrated to inhibit optic axon regeneration, when administered semiweekly by ip injection, and they vary in potency.

The rank order of potency, including colchicine, is vincristine $>$ podophyllotoxin or colchicine $>$ vinblastine. Vincristine is several times more potent than podophyllotoxin and 25 times more potent than vinblastine. Podophyllotoxin is similar in potency to colchicine assayed with the same protocol (Davis et al.. 1984); the ED50 of colchicine is $0.08(0.06$ to 1.0$) \mu \mathrm{g} / \mathrm{g}$. In contrast to colchicine, podophyllotoxin is not lethal at systemic concen-

\section{TABLE}

CONDITIONING LESION EFFECT ON VISUAL RECOVERY EXPRESSED AS THE MEAN TIME TO 50\% RECOVERY OF RIGHT-EYE SigHTEDNESS FOLLOWING OPTIC NERVE CRUSH

\begin{tabular}{|c|c|c|c|}
\hline \multirow{2}{*}{$\begin{array}{c}\text { Condition } \\
\text { lesion interval } \\
\text { (days) }\end{array}$} & \multirow{2}{*}{$\begin{array}{c}\text { Water } \\
\text { temperature } \\
\left({ }^{\circ} \mathrm{C}\right)\end{array}$} & \multicolumn{2}{|c|}{ Days to recovery } \\
\hline & & $\bar{x}$ & $\begin{array}{l}95 \% \text { confidence } \\
\text { limits }\end{array}$ \\
\hline None & 30 & 20.2 & 18.3 to 22.1 \\
\hline 7 & 30 & 19.1 & 16.1 to 21.4 \\
\hline 14 & 30 & 16.8 & 14.1 to 19.6 \\
\hline None & 25 & 29.5 & 26.9 to 32.1 \\
\hline 7 & 25 & 17.3 & 14.1 to 20.4 \\
\hline 42 & 25 & 20.8 & 19.6 to 22.0 \\
\hline
\end{tabular}


trations approximately 3 times its ED50. Maintenance of response was blocked in some fish receiving $0.075 \mu \mathrm{g}$ or $0.1 \mu \mathrm{g} / \mathrm{g}$ of vincristine, which is approximately 4 times the ED50. The $0.1 \mu \mathrm{g}$ dose, which is 5 times the ED50, was lethal to most individuals. Vinblastine and podophyllotoxin had no effects on maintenance of response at doses up to 3 or 4 times their ED50 values.

Picropodophyllotoxin is an isomer of podophyllotoxin which binds to diverse proteins and cellular membranes but has low affinity for tubulin and is a weak inhibitor of microtubules or axonal transport (Wilson and Friedkin, 1967). The ineffectiveness of the $0.5 \mu \mathrm{g} / \mathrm{g}$ dose of picropodophyllotoxin, which is nearly 10 times the ED50 for podophyllotoxin implies that podophyllotoxin acts at least in part by blocking axonal transport or other microtubule functions in the retinal ganglion cells. Similar results were obtained with ip colchicine and its photoisomer, lumicolchicine. These two drugs bind similarly to various cellular membranes but lumicolchicine binds only weakly to tubulin and is several-hundred-fold less potent as an inhibitor of axonal transport in vitro (Banks and Till, 1975; Paulson and McClure, 1975). Optic nerve regeneration is not inhibited by lumicolchicine injected ip at doses up to 25 times the ED50 for colchicine (Davis et al., 1984) or io (Fig. 5). The possibility that lumicolchicine (Price, 1974) and picropodophyllotoxin are excluded from neurons needs investigation.

The toxicity of podophyllotoxin, colchicine, vincristine, and vinblastine could be related to their effects on microtubules in other cells which may participate in the restoration of vision. For example, if proliferation of glia in the optic nerve or tract facilitates axonal regeneration (Neuman et al., 1983; Giulian, 1984), tubulin-binding drugs might inhibit visual recovery by inhibiting mitotic spindles (Wilson and Friedkin, 1967) in the glia.

Our data are the first to permit direct comparison of the in vivo neurotoxicity of these interesting and widely used neuroactive molecules. Previous studies have dealt with only one or several of the six as experimental probes of neuronal processes or as therapeutic drugs. Data from clinical (Desai et al., 1982) and biochemical studies suggest that vincristine is a more potent neurotoxin than vinblastine and that both are more potent than podophyllotoxin or colchicine in vitro $(\mathrm{Ow}-$ ellen et al., 1972; Paulson and McClure, 1975; Ochs and Worth, 1975; Hanson and Edström, 1978). Our finding that vinblastine is less toxic than colchicine or podophyllotoxin may be a result of differences between in vivo and in vitro preparations in uptake of the drug.

Intraocular tubulin-binding drugs. The io experiments show that breakdown of the blood-brain barrier in the regenerating optic nerve does not account for the sensitivity of visual recovery to ip colchicine. The ip route may result in uneven distribution of the drug in the crushed and the intact optic nerve but placing the drug in the vitreous substance presumably results in similar uptake into retinal cells in the experimental and control retinal ganglion cells. The results imply that colchicine intoxication sufficient to inhibit axonal regeneration or the formation of functional synapses is insufficient to block visual function in established optic circuits. The results for vincristine suggest that io doses sufficient to inhibit regeneration also inhibits maintenance of vision. It should be noted that response to the $\mathrm{CS}$ may require minimal retinal input. In addition, owing to its location, the CS presumably produced a large, unfocused field of illumination.

Intraocular administration of tubulinbinding drugs produces toxic effects in retinal cells in other vertebrates. Changes in rat retinal neurons, neuroglia, epithelial cells, and photoreceptors occur within several hours to days following io administration of $0.2 \mu \mathrm{g}$ or more of colchicine (Hansson and Sjöstrand, 1972; Davidson et al., 1983) or $1.0 \mu \mathrm{g}$ or more of vincristine (Hansson, 1972). In domestic cats, $20 \mu \mathrm{g}$ of colchicine results in the disappearance of photoreceptor outer segments and loss of vision within approximately 1 week (Vaccarezza et al., 1973). In rabbit, 
axonal transport in retinal ganglion cells is inhibited by $25 \mu \mathrm{g}$ of colchicine, administered io, and a similar amount of lumicolchicine is ineffective (Price, 1974). Intraocular administration of $10 \mu \mathrm{g}$ but not $5 \mu \mathrm{g}$ of colchicine inhibits orthograde axonal transport of radiolabeled protein in retinal ganglion cells in rainbow trout (Schöstrand et al., 1977). Intraocular vinblastine in rats inhibits orthograde axonal transport in optic axons at doses of $0.5 \mu \mathrm{g}$ or more and retrograde transport at $10 \mu \mathrm{g}$ or more (Bunt and Lund, 1974). The blockade of transport in pigeon optic axons is accompanied by decreased postsynaptic responses to electrical stimulation of the optic nerve, which appears in 3 to 7 days following io injection of colchicine. The inhibition produced by $10 \mu \mathrm{g}$ of the drug is reversed within approximately 14 days following the injection, which is similar to the duration of the inhibiting effect of colchicine on maintenance of visual function in goldfish (Fig. 1).

Visual recovery time as an index of axonal regeneration. Behavioral responses are inherently indirect indexes of neuronal function and it is possible that the time to reappearance of a behavior following optic nerve lesions may underestimate the rate of regeneration of the optic fibers. Edwards et al. (1981) propose that recovery time for some types of behavioral responses are determined by the duration of a recovery lag process, or clock, and not by the rate of axonal outgrowth or the time to reach the target structure. The recovery lag process is inferred to be inherent within the retinal ganglion cells and to be initiated each time that the cell is axotomized. The latter property implies that response indexes of visual recovery which show a conditioning lesion effect, in which recovery time is decreased when the optic nerve is lesioned several days to weeks prior to administration of the test lesion (Edwards et al., 1981), is not limited by a recovery lag process and should be sensitive to the effects of experimental variables that inhibit the rate of axonal regeneration. Conditioning lesions in goldfish optic axons decrease the initial delay to axonal sprouting and nearly double the rate of axonal elongation (McQuarrie and Grafstein, 1980).

Our results show that recovery of the BSR following optic nerve crush is facilitated by a conditioning lesion in fish kept at $25^{\circ} \mathrm{C}$. Finding no facilitation in $30^{\circ} \mathrm{C}$ fish we lowered the temperature to $25^{\circ} \mathrm{C}$ to obtain a slower recovery (Springer and Agranoff, 1977) on the assumption that at $30^{\circ} \mathrm{C}$ the rate of regeneration was too near the maximum to permit detection of a conditioning lesion effect. These results indicate that recovery of thc BSR in $30^{\circ} \mathrm{C}$ fish should be sensitive to delays in axonal regeneration that might be produced by tubulin-binding drugs.

Axon-tracing studies show that following optic nerve crush the contralateral tectum is reinnervated within 14 to 16 days $\left(30^{\circ} \mathrm{C}\right)$ (Springer, 1981; Springer and Agranoff, 1977) which closely coincides with the range of times to reappearance of the BSR: 11 to 21 days $\left(30^{\circ} \mathrm{C}\right)$ as measured semiweekly in a total of approximately $40 \mathrm{fish}$. Ablation of the optic tectum results in the disappearance of most visual behaviors that have been examined (Edwards et al., 1981; Springer et al., 1977) including the BSR (Davis and Schlumpf, 1984) which implies that they are mediated by retinotectal connections. We conclude that the retinotectal connections that are necessary to evoke the BSR with the moving-spot CS reform and regain function very shortly following the arrival of the axons.

\section{REFERENCES}

ATtARDI, D. G., AND SPERRY, R. W. (1963). Preferential selection of central pathways by regenerating optic fibers. Exp. Neurol. 7, 46-64.

BANKS, P., AND TILL, R. (1975). A correlation between the effects of anti-mitotic drugs on microtubule assembly in vitro and the inhibition of axonal transport in noradrenergic neurones. J. Physiol. (London) 252, 283-294.

BenNetT, E. L., Alberti, M. H., AND FloOd, J. F. (1981). Uptake of $\left[{ }^{3} \mathrm{H}\right]$ colchicine into brain and liver of mouse, rat, and chick. Pharmacol. Biochem. Behav. 14, 863-869.

BUNT, A. H., AND LuND, R. D. (1974). Vinblastineinduced blockade of orthograde and retrograde axonal 
transport of protein in retinal ganglion cells. Exp. Neurol. 45, 288-297.

Castle, M. C., Margileth, D. A., and Oliverio, V. T. (1976). Distribution and excretion of $\left[{ }^{3} \mathrm{H}\right]$ vincristine in the rat and dog. Cancer Res. 36, 3684-3689.

DANIELS, M. P. (1972). Colchicine inhibition of nerve fiber formation in vitro. J. Cell Biol. 53, 164-176.

Davidson, C., Green, W. R., AND WONG, V. G. (1983). Retinal atrophy induced by intravitreous colchicine. Invest. Ophthal. Vis. Sci. 24, 301-311.

DAVIS, R. E. (1981). A method of restraining goldfish during conditioning of electric-shock-induced suppression of breathing movements. Behav. Res. Methods Instr. 13, 650-652.

DAvis, R. E., AND BENLOUCIF, S. (1981). Behavioral investigation of neurotoxicity: The effects of colchicine, lumicolchicine and vincristine sulfate on goldfish optic nerve regeneration. Neurotoxicology 2, 419-430.

Davis, R. E., AND SchlumpF, B. E. (1984). Visual recovery in goldfish following unilateral optic tectum ablation: Evidence of competition between optic axons for tectal targets. Behav. Brain Res. 13, 287-291.

Davis, R. E., SCHLumpF, B. E., AND Klinger, P. D. (1984). Systemic colchicine inhibits goldfish optic nerve regeneration. Toxicol. Appl. Pharmacol. 73, 268-274.

DESAI, Z. R., VAN DEN BERG, H. W., BRIDGES, J. M., AND SHANKS, R. G. (1982). Can severe vincristine neurotoxicity be prevented. Cancer Chemother. Pharmacol. 8, 211-214.

EDWARDS, D. L., AlPERT, R. M., AND GRafSTEIN, B. (1981). Recovery of vision in regeneration of goldfish optic axons: Enhancement of axonal outgrowth by a conditioning lesion. Exp. Neurol. 72, 672-687.

Giulian, D. (1984). Peptides from the regenerating central nervous system of goldfish stimulate glia. Proc. Natl. Acad. Sci. USA 81, 3567-3571.

GRAFSTEIN, B., AND FORMAN, D. S. (1980). Intracellular transport in neurons. Physiol. Rev. 60, 1167-1283.

HANSSON, H.-A. (1972). Retinal changes induced by treatment with vincristine and vinblastine. Doc. Ophthal. 31, 65-87.

HANSSON, H.-A., AND SJÖSTRAND, J. (1972). Ultrastructural changes induced in the rat retina by treatment with colchicine. Doc. Ophthal. 31, 29-63.

HANSON, M., AND EDSTRÖM, A. (1978). Mitosis inhibitors and axonal transport. Int. Rev. Cytol. Suppl. 7, 373-402.

KIERNAN, J. A., AND CONTESTABILE, A. (1980). Vascular permeability associated with axonal regeneration in the optic system of the goldfish. Acta Neuropathol. (Berlin) 51, 39-45.

MCQuarRie, I. E., AND GrafsTeIn, B. (1981). Effect of a conditioning lesion on optic nerve regeneration in goldfish. Brain Res. 216, 253-264.

MELliCK, R., KIRKBY, R., SMITH, A. T., AND RATNAVALE, G. (1974). Colchicine and the peripheral nerve. Proc. Aust. Assoc. Neurol. 11, 69-76.
Neuman, D., Yerushalmi, A., ANd Schwartz, M. (1983). Inhibition of non-neuronal cell proliferation in the goldfish visual pathway affects the regenerative capacity of the retina. Brain Res. 272, 237-245.

OCHS, S. (1982). "Axoplasmic Transport And Its Relation To Other Nerve Functions," pp. 278-287. John Wiley \& Sons, New York.

OCHS, S., AND WORTH, R. M. (1975). Comparison of the block of fast axoplasmic transport in mammalian nerve by vincristine, vinblastine and desacetyl vinblastine amide sulfate (DVA). Proc. Amer. Assoc. Cancer Res. 16, 70-81.

OWellen, R. J., OWens, A. H., JR., AND DONIGAN, D. W. (1972). The binding of vincristine, vinblastine and colchicine to tubulin. Biochem. Biophys. Res. Commun. 47, 685-691.

Palanivelu, P., AND Luduena, R. F. (1982). Interactions of the f-Tubulin-Vinblastine complex with colchicine, podophyllotoxin, and $N, N^{\prime}$-Ethylene-bis (iodoacetamide). J. Biol. Chem. 257, 6311-6315.

PAulson, J. C., AND MCClure, W. O. (1975). Inhibition of axoplasmic transport by colchicine, podophyllotoxin, and vinblastine: An effect on microtubules. Ann. N.Y. Acad. Sci. 253, 517-527.

Perisic, M., AND Cuenod, M. (1972). Synaptic transmission depressed by colchicine blockade of axoplasmic flow. Science (Washington, D.C.) 175, 1140-1142.

PrICE, M. T. (1974). The effects of colchicine and lumicolchicine on the rapid phase of axonal transport in the rabbit visual system. Brain Res. 77, 497-501.

Schönhartung, M., Breer, H., RahmanN, H., GuNTER, S., AND RAENER. H. (1977). Colchicine, a novel inhibitor of fast axonal transport without tubulin binding properties. Cytobiologie 16, 106-117.

SPRINGER, A. D., AND AGRANOFF, B. W. (1977). Effect of temperature on rate of goldfish optic nerve regeneration: A radioautographic and behavioral study. Brain Res. 128, 405-415.

Springer, A. D., EASTer, S. S., AND Agranoff, B. W. (1977). The role of the optic tectum in various visually mediated behaviors of goldfish. Brain Res. 128, 393404.

SPRINGER, A. D. (1981). Normal and abnormal retinal projections following the crush of one optic nerve in goldfish (Carassius auratus). J. Comp. Neurol. 199, 87-95.

Tomiwa, K., Hazama, F., and Mikawa, H. (1983). Neurotoxicity of vincristine after the osmotic opening of the blood-brain barrier. Neuropathol. Appl. Neurobiol. 9, 345-354.

WILSON, L., AND FRIEDKIN, M. (1967). The biochemical events of mitosis. II. The in vivo and in vitro binding of colchicine in grasshopper embryos and its possible relation to mitosis. Biochemistry 6, 3126-3135.

Vaccarezza, O. L., Pasqualini, E., and SaAvedra, T. P. (1973). Retinal alterations induced by intravitreous colchicine. Virchows Arch. Abt. B. Zellpathol. 12, $159-167$. 